\title{
Tobacco smoking among government employees in six cities in China
}

\author{
Neil Mehta, ${ }_{1}$ Chen Zhang, ${ }^{2}$ Xinwei Hua, ${ }^{2}$ Pamela Redmon, ${ }^{3}$ Michael Eriksen, ${ }^{3}$ \\ Jeffrey Koplan, ${ }^{2}$ Mohammed Ali ${ }^{1}$
}

- Additional material is available. To view please visit the journal (http://dx.doi.org/ 10.1136/heartasia-2014010557).

${ }^{1}$ Hubert Department of Global Health, Emory University, Atlanta, Georgia, USA ${ }^{2}$ Global Health Institute, Emory University, Atlanta, Georgia, USA

${ }^{3}$ School of Public Health, Georgia State University, Atlanta, Georgia, USA

\section{Correspondence to} Dr Neil Mehta, Hubert Department of Global Health, Emory University, 1518 Clifton Road, Room 7035, Atlanta, GA 30322, USA;

nkmehta@emory.edu

Received 10 July 2014 Revised 24 October 2014 Accepted 20 November 2014

\section{CrossMark}

To cite: Mehta N, Zhang $C$, Hua $X$, et al. Heart Asia 2014:6:179-183.

doi:10.1136/heartasia-2014010557

\section{ABSTRACT \\ Objective Employer-based tobacco control}

interventions have been highly successful in developed countries, and, recently, Chinese officials announced a focus on quitting among government employees. However, there are few data offering estimates of smoking prevalence among government workers from developing nations. In this study, we investigate smoking behaviours among government workers in six Chinese cities stratified by educational attainment and occupational grade.

Design Individual-level study of Chinese government employees.

Data sources Tobacco-Free Cities Initiative of China Tobacco Control Partnership.

Analysis Employed adults aged 18-61 at government worksites in six cities were included ( $\mathrm{N}=6176)$. Prevalence of current and former smoking across educational (postgraduate, graduate, high school, secondary school or less) and occupational (senior executives, mid-level managers, workers) groups were compared.

Results Overall prevalence of male current smoking was $40.7 \%$ (95\% Cl $39.1 \%$ to $42.4 \%$ ). Age-adjusted smoking prevalence was lowest among those with a postgraduate degree $(26.2 \%$ (95\% Cl $21.0 \%$ to $31.4 \%)$ ) compared with those with lower levels of education (college (39.8\%; $37.7 \%$ to $41.8 \%$ ); high school $(51.0 \% ; 95 \% \mathrm{Cl} 45.0 \%$ to $57.0 \%)$; secondary or less (45.1\%; $95 \% \mathrm{Cl} 40.3 \%$ to $49.8 \%))$. There was no evidence of an association between current smoking and occupational grade. Prevalence of smoking was low in women (1.5\%).

Conclusions Smoking prevalence among male government employees at all levels of education was high and patterned by educational attainment.

Government initiatives to address tobacco control among employees should consider targeted interventions for different educational levels.

\section{INTRODUCTION}

In 2010, smoking and second-hand exposure to tobacco accounted for 6.3 million or $12 \%$ of all deaths worldwide. ${ }^{1}$ Tobacco was the leading risk factor for global death and disability among men and was second highest among women. ${ }^{2}$ With over 300 million smokers, ${ }^{3}{ }^{4}$ China accounts for much of the world's tobacco-related morbidity and mortality. In 2005, an estimated 673000 deaths among adults aged 40 or above in China were attributed to cigarette smoking. ${ }^{5}$ Along with diet and hypertension, cigarette smoking is estimated to be a leading cause of disability-adjusted life years lost in 2010 for China. ${ }^{6}$
China is the world's largest producer of tobacco products. $^{7}$ The Chinese Communist Party recently announced that government workers are to lead by example in their efforts to quit smoking-specifically, officials should not smoke in public or purchase tobacco using public funds, and smoking has been banned at many workplace offices, meeting rooms and cafeterias, with stricter fines, shaming and enforcement promised. ${ }^{8} 9$ Although China had signed the WHO's Framework Convention on Tobacco Control (FCTC), policies to address tobacco were not widely implemented and enforced in China. ${ }^{10}$ China scored poorly in a recent WHO report on FCTC implementation, ${ }^{11}$ and these new government mandates may be in response to this pressure.

Epidemiological analyses that investigate the risk factors for tobacco use are helpful in developing appropriate prevention and control policies and programmes. For example, very little is known about smoking levels among government employees in China-specifically, what was the prevalence before these top-down policies were announced, and how does prevalence in this group compare with prevalence in the general population? In addition, examining the prevalence of tobacco use in different socioeconomic groups helps to prioritise intervention approaches. Previous studies from many high-income countries have shown higher prevalence of tobacco use in lower socioeconomic status groups. ${ }^{12-14}$ Studies focusing on low- and middle-income countries also often document a negative association between socioeconomic status and smoking prevalence, although there appears to be more heterogeneity in the magnitude and direction of this association than in high-income countries. $^{15} 16$

The two largest sources of national-level data on smoking in China are the World Health Survey (2002-2003) and the Global Adult Tobacco Survey (GATS, 2008-2010). Studies based on these data indicate that smoking is negatively associated with education and an asset-based index. ${ }^{16}{ }^{17}$ Studies from rural China have demonstrated higher tobacco use and second-hand exposure among tobacco farmers compared with individuals in other occupations or farming other products, less-educated individuals, and poorer communities. $^{18} 19$

Little is known about patterns of tobacco use across different urban employment sectors in China. An understanding of patterns in this specific employment sector will help guide employer-based tobacco control programming, which has been shown to be highly effective. ${ }^{2021}$ We collected and 
analysed data from large government sector employers in six cities in China. We focus on two distinct, yet related, dimensions of socioeconomic position (SEP): educational attainment and occupational status. ${ }^{22}{ }^{23}$ Education, set relatively early in life, influences one's human and social capital, including cognitive factors that can influence lifetime behavioural choices. Occupational status is associated with one's social networks and material resources, both of which may also be related to behavioural choices. These recent data will also be of particular interest given the rapid socioeconomic, demographic and health transitions occurring in China.

\section{METHODS}

\section{Data and sample}

Data were from the Tobacco-Free Cities Initiative of Emory University's Global Health Institute-China Tobacco Control (GHI-CTC) Partnership. ${ }^{24}$ The aim of the partnership, which was established in 2008 , is to reduce the health, social, environmental and economic burdens of tobacco through several initiatives implemented in 17 Chinese cities. ${ }^{25}$ The 17 grantee cities were allowed to decide where to focus their efforts based on each city's unique context. Each city conducted a systematic situational analysis to better understand the extent of tobacco use problems and existing tobacco control efforts and to identify potential interventions and partners. The grantees selected the programme goals based on their perceived ability to achieve the greatest initial impact and the potential for social norm change, and each grantee had to demonstrate impacts of their programme through monitoring and evaluation.

Our analysis was limited to six of the 17 Chinese cities. These were the six cities that addressed tobacco control in government offices: Changchun, Kelamayi, Nanning, Suzhou, Tangshan, Yinchuan. Baseline pre-intervention data were collected at selected worksites in each city in 2011-2012. Potential participants were identified using stratified cluster sampling at each site. Response rate ranged from $75 \%$ to $91 \%$ : Changchun, 91\%; Kelamayi, 84\%; Nanning, 77\%; Suzhou, 75\%; Tangshan, $85 \%$; and Yinchuan, $87 \%$. A total of 7251 respondents were surveyed at worksites. We excluded from our analysis 1075 $(14.8 \%)$ respondents who had missing data on at least one covariate used in the analysis, and the final analytical sample included 6176 respondents (3321 male and 2855 female).

Using interviewer-administered questionnaires, data were collected to ascertain sociodemographic characteristics, smoking behaviours, worksite smoking policies, and knowledge, attitudes and perceptions about smoking risks. Data were collected by local grantees, which were most commonly city-level Centers for Disease Control (CDCs) and Health Education Institutes. Further details about the GHI-CTC Partnership and datacollection methods have been published separately. ${ }^{25}$

The project received institutional review board approval from Emory University and from local institutional review boards in China. This study was a secondary analysis of deidentified data.

\section{Smoking and SEP measures}

Smoking status at the time of survey was assessed from questions about current and past tobacco smoking behaviour. Current smokers were defined as those who reported current smoking daily or less than daily. Former smokers were those who reported not being current smokers, but who had smoked tobacco in the past. Educational attainment was defined by the highest level achieved: secondary school or less, high-school graduate, college graduate, or postgraduate. Three occupational categories were assessed: worker, mid-level manager, and senior executive or leader.

\section{Statistical analysis}

Data were pooled from the six cities. Descriptive statistics of the sample, including smoking status, were presented by sex. We then limited the analysis to men because of the low prevalence of current smoking among women (1.5\%). Separately, we estimated the proportion of current smokers within each educational category and each occupational category. These estimates were age-adjusted using as a standard the mean age distribution of the men in the sample (using the following age groupings: 18-29, 30-49 and 50-61 years). Statistical comparisons were made using $\chi^{2}$ tests for the differences in proportions. The $95 \%$ CIs shown account for clustering at both the city and worksite level. Statistical significance was defined as a two-tailed $\mathrm{p}<0.05$. All analyses were conducted using SAS (V.9).

\section{RESULTS}

Table 1 provides descriptive characteristics of the sample by sex. The mean age of the men was 39.2 years, and the mean age of the women was 36.4 years. The majority of the sample $(76.7 \%$ of men and $81.7 \%$ of women) had at least a college degree (college graduate or postgraduate), reflecting the high educational level of the sample. Despite the high educational level of the sample, $67.8 \%$ (men) and $82.3 \%$ (women) were classified as workers. Only $5.5 \%$ of men and $1.9 \%$ of women were senior executives/leaders.

Table 1 also provides the prevalence of different smoking statuses. The prevalence of current smoking was low among women $(1.5 \%)$. For men, $40.7 \%$ of respondents were current smokers. Only $5.7 \%$ of men and a small percentage $(0.4 \%)$ of women were former smokers.

Table 2 presents educational and occupational gradients for current smoking prevalence among men. Focusing on the age-adjusted estimates, the highest smoking prevalence was recorded for those who were high-school graduates $(51.0 \%$ (95\% CI $45.0 \%$ to $57.0 \%)$ ); however, this prevalence was similar to that of the lowest educational category (those with secondary school or less, $45.1 \%$ (95\% CI $40.3 \%$ to $49.8 \%)$ ). Those with a postgraduate education had the lowest smoking prevalence $(26.2 \%$ (95\% CI $21.0 \%$ to $31.4 \%)$ ). The difference in smoking prevalence between the lowest and highest educated groups was statistically significant $(\mathrm{p}<0.001)$. We did not detect statistically significant differences $(p>0.05)$ across the three lowest educational groups, thus most of the gradient is attributable to the lower smoking prevalence among those with a postgraduate degree compared with the three other educational categories. Age-stratified results revealed a similar pattern among those aged less than 40 compared with those aged 40 and above (data not shown).

In contrast with the pattern across educational groups, gradients in current smoking prevalence were not evident across occupational groups (about 40\% current smoking prevalence for each group). Multivariate models adjusting for age, marital status and knowledge about whether smoking causes serious disease produced substantively similar results to the patterns we report here (data not shown). Online supplementary appendix 1 provides the distribution of smoking status in individual cities. Online supplementary appendix 2 shows educational and occupational gradients by city and highlights that the gradients were generally similar across cities. 
Table 1 Descriptive characteristics of the sample by sex; ages 18-61

\begin{tabular}{|c|c|c|c|c|}
\hline \multirow[b]{2}{*}{ Characteristic } & \multicolumn{2}{|c|}{ Male $(\mathrm{N}=3321)$} & \multicolumn{2}{|c|}{ Female $(\mathrm{N}=2855)$} \\
\hline & $\%$ or mean & $95 \% \mathrm{Cl}$ & $\%$ or mean & $95 \% \mathrm{Cl}$ \\
\hline Age, mean (SD) & $39.2(9.7)$ & 37.6 to 40.8 & $36.4(8.8)$ & 34.8 to 38.0 \\
\hline \multicolumn{5}{|l|}{ Smoking status, $\%$} \\
\hline Current & 40.7 & 39.1 to 42.4 & 1.5 & 1.1 to 2.0 \\
\hline Former & 5.7 & 4.9 to 6.5 & 0.4 & 0.2 to 0.6 \\
\hline Never & 53.6 & 51.9 to 55.3 & 98.1 & 97.6 to 98.6 \\
\hline \multicolumn{5}{|l|}{ Education, \% } \\
\hline Secondary school or less & 14.1 & 12.9 to 15.3 & 10.1 & 9.0 to 11.2 \\
\hline High-school graduate & 9.2 & 8.2 to 10.2 & 8.2 & 7.2 to 9.2 \\
\hline College graduate & 66.6 & 65.0 to 68.2 & 73.4 & 71.8 to 75.0 \\
\hline Postgraduate & 10.1 & 9.1 to 11.1 & 8.3 & 7.3 to 9.3 \\
\hline \multicolumn{5}{|l|}{ Occupation, \% } \\
\hline Worker & 67.8 & 66.2 to 69.4 & 82.3 & 80.9 to 83.7 \\
\hline Mid-level manager & 26.7 & 25.2 to 28.2 & 15.8 & 14.5 to 17.1 \\
\hline Senior executive or leader & 5.5 & 4.7 to 6.3 & 1.9 & 1.4 to 2.4 \\
\hline \multicolumn{5}{|l|}{ Marital status, \% } \\
\hline Married & 83.7 & 82.4 to 85.0 & 79.3 & 77.8 to 80.8 \\
\hline Single & 16.3 & 15.0 to 17.6 & 20.7 & 19.2 to 22.2 \\
\hline
\end{tabular}

\section{DISCUSSION}

These 2011-2012 survey data from six different cities in China show a high prevalence of current smoking among men working in the government sector. Smoking was rare among women $(<2 \%)$. Among male government employees, the lowest educated groups were nearly twice as likely to be current smokers as the highest educated; however, when stratified by occupation, there were no differences between workers, managers and executives in smoking prevalence.

Our findings suggest that smoking status is associated with educational level, but not occupational grade, among male government employees. However, we did not find significant differences in prevalence among the three lowest educational groups, which represented about $90 \%$ of the sample. It is clear that

Table 2 Age-unadjusted and age-adjusted prevalence of current smoking among male government employees by education and occupation status; ages 18-61 ( $\mathrm{N}=3321)$

\begin{tabular}{|c|c|c|c|c|}
\hline \multirow[b]{2}{*}{ Sector } & \multicolumn{2}{|c|}{ Age-unadjusted } & \multicolumn{2}{|c|}{ Age-adjusted } \\
\hline & $\begin{array}{l}\text { Per } \\
\text { cent }\end{array}$ & $95 \% \mathrm{Cl}$ & $\begin{array}{l}\text { Per } \\
\text { cent }\end{array}$ & $95 \% \mathrm{Cl}$ \\
\hline \multicolumn{5}{|l|}{ Education } \\
\hline Secondary school or less & 46.1 & 41.5 to 50.6 & 45.1 & 40.3 to 49.8 \\
\hline High-school graduate & 52.5 & 46.8 to 58.1 & 51.0 & 45.0 to 57.0 \\
\hline College graduate & 40.2 & 38.2 to 42.3 & 39.8 & 37.7 to 41.8 \\
\hline Postgraduate & 25.9 & 21.2 to 30.6 & 26.2 & 21.0 to 31.4 \\
\hline \multicolumn{5}{|l|}{ Occupation } \\
\hline Worker & 40.3 & 38.3 to 42.3 & 40.7 & 38.7 to 42.8 \\
\hline Mid-level manager & 42.2 & 38.9 to 45.4 & 42.3 & 37.8 to 46.8 \\
\hline $\begin{array}{l}\text { Senior executive or } \\
\text { leader }\end{array}$ & 38.8 & 31.7 to 45.9 & 40.1 & 30.5 to 49.7 \\
\hline
\end{tabular}

Note: age-standardised estimates were standardised using the mean age distribution of all men in the sample (using the following groupings: 18-29, 30-49 and 50-61 years). Source: Global Health Institute-China Tobacco Control (GHI-CTC) Evaluation Data, 2011-2012. those with a postgraduate degree, representing about $10 \%$ of the sample, had the lowest levels of smoking among all groups. These findings are consistent with a study of 19969 industrial workers and their family members across 10 sites in India. ${ }^{26}$ In that study, prevalence of tobacco smoking was associated with education, but not occupational grade.

Our estimates for current smoking prevalence were similar to findings from the 2010 GATS conducted in China. In those high-response-rate household surveys which used a global standardised methodology and recruited 13354 participants, smoking prevalence among urban men and women was $49 \%$ and $3 \%$, respectively. ${ }^{4}$ This comparison suggests that smoking levels among male government employees in our study are almost 10 percentage points lower than among men in the overall population. Notably, across occupational groups, GATS data showed a prevalence of tobacco smoking that was almost $70 \%$ among machine operators, while about $41 \%$ of government workers smoked in our study. Similarly, from GATS, just over $50 \%$ of leaders of organisations smoked, which is similar to $40 \%$ of individuals in senior leader and executive roles in government who smoked from our data.

Differences in smoking prevalence between those with and without a postgraduate education in our data were of the order of 10-20 percentage points. However, interventions for the most educated are still needed, as more than a quarter of the highest-educated male government employees are current smokers. In addition, in the GATS data, it was found that 53\% of current smokers reported initiating tobacco use before the age of 20. This suggests that greater emphasis on tobacco prevention may be necessary, perhaps during teenage and early adulthood through educational institutions.

In addition to health burdens, tobacco use has major economic impacts, especially among lower SEP groups, imposing high health expenditures and opportunity costs on households. This has sequentially broader impacts and potentially stifles micro- and macro-economic development. ${ }^{27}{ }^{28}$ Higher tobacco smoking among the least educated may also reinforce health inequalities across generations. ${ }^{28} 29$ 
Advocacy at the employer level, especially mandated and enforced strictly by the Chinese government with regard to their own employees, can have major impacts. In countries such as the USA, there is a large literature on the excess absenteeism, presenteesim, smoking breaks, healthcare, and pension costs borne by employers for smoking employees. ${ }^{30}$ The economic argument that tobacco use among employees is costly for employers has resulted in tobacco-free workplaces, tobacco-free hiring practices, nicotine screenings, financial penalties for smoking employees, and encouraging smokers to register and attend cessation programmes. ${ }^{21} 3031$

Since the tobacco industry itself has strong influences in China, and the Chinese government has a stake in the industry, tobacco regulation in China remains challenging, especially in provinces where tobacco sales contribute to government revenues. ${ }^{32}$ As such, this government employee mandate comes at a good time. It is also another example of 'policy experimental gradualism' in China. ${ }^{33}$ China has long used the approach of implementing policies and evaluating on-the-ground impacts, feeling its way through policy reforms, rather than rigorously assessing policies before implementation. ${ }^{34}$ Similarly here, implementation precedes analysis, and our timely data can serve as a baseline before the government employee mandates regarding tobacco. Repeated surveys at these worksites in the years to come, in a quasi-experimental fashion, may at least provide data and lessons that could be learned from the experimental approach to China's policy innovation and implementation.

There are some limitations that must be considered in interpreting our findings. Our data were not collected from representative population samples in the cities surveyed; these data were from respondents in a specific employment sector and included a mix of random and convenience sampling across cities and worksites. Data for this study were all self-reported. However, most adult tobacco surveys, such as GATS, use intervieweradministered questionnaires to assess prevalence of tobacco use and these have been correlated with serum cotinine levels. ${ }^{35-37}$ Also, most studies evaluating the reliability of self-reported smoking behaviours have been conducted in western countries. However, cultural-specific norms as well as gender differences may play a role in reporting behaviours. Social norms in China may have kept smoking prevalence low among women relative to men. ${ }^{38}$ Norms discouraging smoking among women may lead to under-reporting of smoking. The similar levels of female smoking observed in GATS and our study (around 2-3\%) may therefore be an underestimate of the actual prevalence. We did not have data regarding second-hand smoke exposure, which is common in China.

To provide greater details, data stratified by city are presented in online appendices, although sample sizes precluded a crosscity comparison. Our analyses involved categorising individuals into SEP groups, and could not account for possible heterogeneity within the SEP groups defined. Furthermore, educational status and occupation do not comprehensively characterise all the social and economic factors that influence tobacco use. In particular, cultural practices, parents' smoking habits, peer group pressures among teens, the addictive properties of tobacco, availability and costs of tobacco products, climate, work environment and conditions, and governmental policies all probably influence uptake and use. Future studies should collect data that reflect these different aspects and investigate these further.

The limitations are counterbalanced by some important strengths. Data for this study were collected from six cities, and the analysis included a large sample size, providing some generalisability to all Chinese government workers. Data were collected using a standardised questionnaire across all work sites and cities. Finally, we used multiple indicators of SEP.

\section{CONCLUSIONS}

Prevalence of tobacco smoking is high among male government workers at all educational levels, and is lower among those with a postgraduate degree compared with all others. To address high tobacco use, especially among lower-educated individuals, appropriate prevention and cessation programmes or enforcement of new policies are needed. In addition, further implementation research is needed to evaluate programmes and policies that have recently been, or are being, implemented in China. In particular, it will be important to identify factors associated with successful tobacco prevention and cessation (eg, enforcement) for all SEP groups.

Contributors NM and MA conceived the project and wrote an initial draft of the manuscript. CZ and XH conducted the statistical analysis. All authors edited the initial manuscript and contributed to the scientific content.

Funding This publication is based on research funded by (or in part by) the Bill and Melinda Gates Foundation (Grant No 51437). The findings and conclusions contained within are those of the authors and do not necessarily reflect positions or policies of the Bill and Melinda Gates Foundation.

Competing interests None.

Ethics approval Emory University.

Provenance and peer review Not commissioned; externally peer reviewed.

Data sharing statement Researchers may contact Emory University's Global Health Institute to inquire about the availability of data.

\section{REFERENCES}

1 Lozano R, Naghavi M, Foreman K, et al. Global and regional mortality from 235 causes of death for 20 age groups in 1990 and 2010: a systematic analysis for the Global Burden of Disease Study 2010. Lancet 2012;380:2095-128.

2 Lim SS, Vos T, Flaxman AD, et al. A comparative risk assessment of burden of disease and injury attributable to 67 risk factors and risk factor clusters in 21 regions, 1990?2010: a systematic analysis for the Global Burden of Disease Study 2010. Lancet 2012;380:2224-60

3 Li Q, Hsia J, Yang G. Prevalence of smoking in China in 2010. N Eng/ J Med 2011;364:2469-70.

4 Global Tobacco Surveillance System. Global Adult Tobacco Survey (GATS): Fact Sheet China 2010. Secondary Global Adult Tobacco Survey (GATS): Fact Sheet China 2010-2012. http://www.who.int/tobacco/surveillance/en_tfi_china_gats_factsheet_ 2010.pdf

5 Gu D, Kelly TN, Wu X, et al. Mortality attributable to smoking in China. N Engl J Med 2009;360:150-9.

6 Institute of Health Metrics and Evaluation. GBD Profile: China. Secondary GBD Profile: China 2013. http://www.healthdata.org/sites/default/files/files/country_ profiles/GBD/ihme_gbd_country_report_china.pdf

7 Mackay J. Beyond the clouds - tobacco smoking in China. JAMA 1997;278:1531-2.

8 Wee D. Communist Party's smoking ban no longer a yawning matter for officials. Secondary Communist Party's smoking ban no longer a yawning matter for officials January 10, 2014. http://www.scmp.com/news/china/article/1402188/communistpartys-smoking-ban-no-longer-yawning-matter-officials

9 Rajagopalan M, Yan H. China says Communist Party leaders must not smoke in public, help colleagues quit. Secondary China says Communist Party leaders must not smoke in public, help colleagues quit December 30. 2014. http://www.reuters com/article/2013/12/30/us-china-smoking-idUSBRE9BT04320131230

10 Samet JM. Invited commentary: the challenge of tobacco control in China. Am J Epidemiol 2014;179:1071-3.

11 World Health Organization. WHO Report on the Global Tobacco Epidemic, 2013: Enforcing Bans on Tobacco Advertising, Promotion and Sponsorship. Geneva, Switzerland, 2013

12 Break Free Alliance. Smoking in Low Socioeconomic Status Populations: Prevalence, Health Impact, Challenges and Recommendations. Secondary Smoking in Low Socioeconomic Status Populations: Prevalence, Health Impact, Challenges and Recommendations 2009. http://healthedcouncil.org/breakfreealliance/ADEPTreport. html

13 Siahpush $M$, McNeill $A$, Borland $R$, et al. Socioeconomic variations in nicotine dependence, self-efficacy, and intention to quit across four countries: findings from 
the International Tobacco Control (ITC) Four Country Survey. Tob Control 2006;15 (Suppl 3):iii71-5.

14 Siahpush M, McNeill A, Hammond D, et al. Socioeconomic and country variations in knowledge of health risks of tobacco smoking and toxic constituents of smoke: results from the 2002 International Tobacco Control (ITC) Four Country Survey. Tob Control 2006;15(Suppl 3):iii65-70.

15 Fleischer NL, Diez Roux AV, Hubbard AE. Inequalities in body mass index and smoking behavior in 70 countries: evidence for a social transition in chronic disease risk. Am J Epidemiol 2012;175:167-6.

16 Harper S, McKinnon B. Global socioeconomic inequalities in tobacco use: internationally comparable estimates from the World Health Surveys. Cancer Causes Control 2012;23(Suppl 1):11-25.

17 Palipudi KM, Gupta PC, Sinha DN, et al. Social determinants of health and tobacco use in thirteen low and middle income countries: evidence from Global Adult Tobacco Survey. PLoS ONE 2012;7:e33466.

18 Cai L, Wu X, Goyal A, et al. Multilevel analysis of the determinants of smoking and second-hand smoke exposure in a tobacco-cultivating rural area of southwest China. Tob Control 2013;22(Suppl 2):ii16-20.

19 Cai L, Wu X, Goyal A, et al. Patterns and socioeconomic influences of tobacco exposure in tobacco cultivating rural areas of Yunnan Province, China. BMC Public Health 2012;12:842.

20 Fichtenberg CM, Glantz SA. Effect of smoke-free workplaces on smoking behaviour: systematic review. BMJ 2002;325:188.

21 National Business Group on Health. Tobacco: The Business of Quitting. Secondary Tobacco: The Business of Quitting December 2013. http://www.businessgroup health.org/tobacco/

22 Alwin DF, Wray LA. A life-span developmental perspective on social status and health. J Gerontol B Psychol Sci Soc Sci 2005;60(Suppl_Special_Issue_2):S7-14.

23 Galobardes B, Smith GD, Lynch JW. Systematic review of the influence of childhood socioeconomic circumstances on risk for cardiovascular disease in adulthood. Ann Epidemiol 2006;16:91-104.

24 Emory University. China Tobacco Control Partnership. Secondary China Tobacco Control Partnership 2013. http://www.ghi-ctp.emory.edu/
25 Redmon P, Koplan J, Eriksen $\mathrm{M}$, et al. The role of cities in reducing smoking in China. Int J Environ Res Public Health 2014;11:10062-75.

26 Reddy KS, Prabhakaran D, Jeemon P, et al. Educational status and cardiovascular risk profile in Indians. Proc Natl Acad Sci USA 2007;104:16263-8.

27 Stuckler D, Basu S, McKee M. Drivers of inequality in Millennium Development Goal progress: a statistical analysis. PLoS Med 2010;7:e1000241.

28 Abegunde DO, Mathers CD, Adam T, et al. The burden and costs of chronic diseases in low-income and middle-income countries. Lancet 2007;370:1929-38.

29 Abegunde DO, Stanciole AE. The economic impact of chronic diseases: how do households respond to shocks? Evidence from Russia. Soc Sci Med 2008;66:2296-307.

30 Berman M, Crane R, Seiber E, et al. Estimating the cost of a smoking employee. Tob Control 2014;23:428-33.

31 Ebeling A. More Employers Shun Tobacco Users. Secondary More Employers Shun Tobacco Users July 2013. http://www.forbes.com/sites/ashleaebeling/2013/03/07/ more-employers-shun-tobacco-users/

32 Redmon P, Chen LC, Wood JL, et al. Challenges for philanthropy and tobacco control in China (1986-2012). Tob Control 2013;22(Suppl 2):ii4-8.

33 Rodrik D. The new development economics: we shall experiment, but how shall we learn? In: Cohen J, Easterly W. eds. What works in development: thinking big and thinking small. Washington DC: The Brookings Institution, 2009:24-47.

34 Heilmann S. Policy experimentation in China's Economic Rise. Stud Comp Int Dev 2008;43:1-26.

35 Klebanoff MA, Levine RJ, Clemens JD, et al. Serum cotinine concentration and self-reported smoking during pregnancy. Am J Epidemiol 1998;148:259-62.

36 Vartiainen $E$, Seppala $T$, Lillsunde $P$, et al. Validation of self reported smoking by serum cotinine measurement in a community-based study. J Epidemiol Community Health 2002;56:167-70.

37 Wong SL, Shields M, Leatherdale S, et al. Assessment of validity of self-reported smoking status. Secondary Assessment of validity of self-reported smoking status 2012. http://www.statcan.gc.ca/pub/82-003-x/2012001/article/11625-eng.pdf

38 Hermalin Al, Lowry D. The age prevalence of smoking among Chinese women: a case of arrested diffusion? Ann Arbor: Population Studies Center, University of Michigan, 2010 